\title{
“D-cell hypothesis” of schizophrenia: Possible theory for mesolimbic dopamine hyperactivity
}

\author{
Keiko Ikemoto ${ }^{1,2,3}$ \\ ${ }^{1}$ Department of Neuropsychiatry, School of Medicine, Fukushima Medical University, Fukushima, Japan \\ ${ }^{2}$ Department of Psychiatry, Iwaki Kyoritsu General Hospital, Iwaki, Japan \\ ${ }^{3}$ Department of Legal Medicine, Shiga University of Medical Science, Otsu, Japan \\ Email: ikemoto@fmu.ac.jp,ikemoto@iwaki-kyoritsu.iwaki.fukushima.jp
}

Received 24 February 2012; revised 1 April 2012; accepted 15 April 2012

\begin{abstract}
The author proposes a new "D-cell hypothesis" for mesolimbic dopamine (DA) hyperactivity of schizophrenia. The "D-cell" is defined as "non-monoaminergic aromatic L-amino acid decarboxylase (AADC)-containing cell”. D-cells produce trace amines, such as tyramine and $\beta$-phenylethylamine, and may also take up amine precursors and convert them to amines by decarboxylation. Trace amine-associated receptor, type 1 (TAAR1), a subtype of trace amine receptors, has a large number of ligands, including tyramine, $\beta$ phenylethylamine and methamphetamine, that influence on human mental states, and is now regarded to be a target receptor for novel neuroleptics. Recent studies revealed that the reduced stimulation of TAAR1 on $D A$ neurons in the midbrain ventral tegmental area (VTA) increased firing frequency of VTA DA neurons. The author and her colleagues reported the decrease of $D$-neurons in the striatum and nucleus accumbens of postmortem brains of patients with schizophrenia. This may imply the decrease of trace amine synthesis, resulting the reduced stimulation of TAAR1 on terminals of midbrain VTA DA neurons, and may lead to mesolimbic DA hyperactivity in schizophrenia. The decrease of striatal D-neurons of postmortem brains of schizophrenia is supposed to be due to neural stem cell dysfunction in the subventricular zone of lateral ventricle. The decrease of striatal D-neurons and acts of TAAR1 signals on DA neurons might explain mesolimbic DA hyperactivity of schizophrenia.
\end{abstract}

Keywords: Dopamine; D-Neuron; Ventral Tegmental Area; Schizophrenia; TAAR1

\section{INTRODUCTION}

Dopamine (DA) dysfunction [1,2], glutamate dysfunction $[3,4]$, neurodevelopmental deficits $[5,6]$, or neural stem cell dysfunction $[7,8]$ are well-known hypotheses for etiology of schizophrenia. DA dysfunction hypothesis suggests that mesolimbic DA hyperactivity causes positive symptoms such as paranoid-hallucinatory state of schizophrenia [1,2]. It is also explained by the efficacy of DA D2 blocker for paranoid-hallucinatory state, and also by hallucinogenic acts of DA stimulants, including methamphetamine or amphetamine [1,2]. Glutamate dysfunction theory was induced by the fact that intake of phencyclidine (CPC), an antagonist of NMDA receptor, produce equivalent to negative symptoms of schizophrenia, such as withdrawal or flattened affect, as well as positive symptoms [3,4]. The neurodevelopmental deficits hypothesis implicates that schizophrenia is the consequence of prenatal abnormalities resulting from the interaction of genetic and environmental factors [5,6]. Neural stem cell dysfunction has also been shown to be a cause of schizophrenia $[7,8]$.

Although mesolimbic DA hyperactivity [1,2] has been well documented in pathogenesis of schizophrenia, the molecular basis of this mechanism has not yet been detailed. In the present article, the author hypothesized the involvement of striatal D-neurons and trace amine-associated receptor, type 1 (TAAR1) in the pathogenesis of mesolimbic DA hyperactivity of schizophrenia [9].

\section{D-CELL}

The "D-cell" was described, by Jaeger et al. [10] in 1983, in the rat central nervous system, and was defined "nonmonoaminergic aromatic L-amino acid decarboxylase (AADC)-containing cells" [10]. Namely, the D-cell contains AADC but not dopaminergic nor serotonergic [10]. D-cells produce trace amines [11,12], and may also act as an APUD (amine precursor uptake and decarboxylation) system that takes up amine precursors and convert them to amines by decarboxylation [13]. The localizations of D-cells were specified into 14 groups, from D1 (the spinal cord) to D14 (the bed nucleus of stria terminalis), in caudo-rostral orders of the rat central nervous 
system, using AADC immunohistochemistry [14,15]. In this usage of classification term, "D" means decarboxylation. In rodents [13,16,17], a small number of D-cells in the striatum were rostrally described and confirmed to be neurons by electron-microscopic observation [13].

I reported in 1997, “dopa-decarboxylating neurons specific to the human striatum [18-21]", that is, "D-neurons" in the human striatum [20,22] (classified to be D15) [20], and later in 2003, and reduction of the number of D-neurons in the striatum and nucleus accumbens of patients with schizophrenia [9,22].

\section{TRACE AMINE-ASSOCIATED RECEPTOR, TYPE 1 (TAAR1)}

Cloning of trace amine receptors in 2001 [23,24], elicited enormous efforts for exploring signal transduction of these G-protein coupled receptors whose genes are located on chromosome focus 6q23.1 [25]. The receptors are shown to co-localize with dopamine or adrenaline transporters in monoamine neurons, and to modulate the functions of monoamines [26-28].

The trace amine-associated receptor, type 1 (TAAR1) has a large number of ligands, including tyramine, $\beta$ phenylethylamine (PEA) and psychostimulants, for example, methamphetamine, 3,4-methylenedioxymethamphetamine (MDMA) and lysergic acid diethylamide (LSD) [23, $25,29]$, and is now a target receptor for exploring novel neuroleptics [30,31].

TAAR1 knockout mice showed schizophrenia-like behaviors, with a deficit in prepulse inhibition [32]. TAAR1 knockout mice showed greater locomotor response to amphetamine and released more DA (and noradrenaline) in response to amphetamine than wild type mice [32]. It has been shown that TAAR1 has a thermoregulatory function [33].

It was clarified that increased stimulation of TAAR1 receptors on cell membranes of DA neurons in the midbrain ventral tegmental area (VTA) reduces firing frequency of VTA DA neurons [30-32].

\section{A NEW "D-CELL HYPOTHESIS" OF SCHIZOPHRENIA}

A new theory, "D-cell hypothesis", for explaining mesolimbic DA hyperactivity in pathogenesis of schizophrenia is shown in Figure 1.

In brains of patients with schizophrenia, dysfunction of neural stem cells in the subventricular zone of lateral ventricle may cause the decrease of D-neurons in the nucleus accumbens $[8,34]$. This may lead to the decrease of the amounts of trace amines in the nucleus, though direct evidences have not yet been demonstrated. Enlargement of the lateral ventricle [35,36], a usual finding documented in brain imaging studies of schizophrenia,

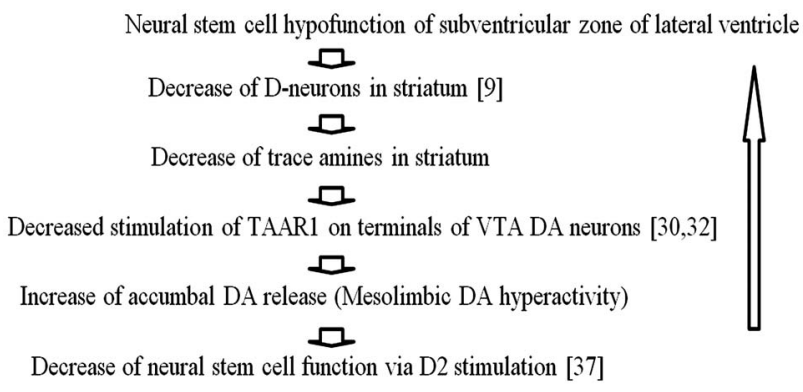

Figure 1. "D-cell hypothesis” of schizophrenia.

may also be due to dysfunction of neural stem cells of the subventricularzone $[7,8]$.

The reduction of TAAR1 stimulation on DA terminals of VTA DA neurons, caused by decrease of striatal trace amine synthesis, may increase the firing frequency of VTA DA neurons [30,32]. This may lead to the increase of DA release in the nucleus accumbens, that is, mesolimbic DA hyperactivity.

It has been shown that D2 stimulation of neural stem cells in the striatum inhibited forebrain neural stem cell proliferation [37]. Then, striatal DA hyperactivity may lead to additional decrease of D-neurons, which might induce additional hyperactivity of mesolimbic DA system by above mentioned mechanisms. Actions of D2 blocking agents in pharmacotherapy of schizophrenia might partially be explained by the decrease of inhibition to forebrain neural stem cell proliferations. It might be consistent with the clinical evidences that D2 blocker is effective for the treatment of schizophrenia.

\section{CONCLUSION}

The D-cell, the trace amine-producer, might be a clue for pathogenesis of DA hyperactivity of schizophrenia. Further exploration of signal transduction of the D-neuron is essential.

\section{ACKNOWLEDGEMENTS}

This present study was supported by Grant-in-Aid for Scientific Research from Japan Society for the Promotion of Science (C-22591265).

\section{REFERENCES}

[1] Hokfelt, T., Ljungdahl, A., Fuxe, K. and Takashima, N. (1974) Dopamine nerve terminals in the rat limbic cortex: Aspects of the dopamine hypothesis of schizophrenia. Science, 184, 177-179. doi:10.1126/science.184.4133.177

[2] Toru, M., Nishikawa, T., Mataga, N. and Takashima, N. (1982) Dopamine metabolism increases in post-mortem schizophrenic basal ganglia. Journal of Neural Transmission, 54, 181-191. doi:10.1007/BF01254928

[3] Watis, L., Chen, S.H., Chua, H.C., Chong, S.A. and Sim, K. (2008) Glutamatergic abnormalities of the thalamus in 
schizophrenia: A systematic review. Journal of Neural Transmission, 115, 493-511. doi:10.1007/s00702-007-0859-5

[4] Olbrich, H.M., Valerius, G., Rüsch, N., Buchert, M., Thiel, T., Hennig, J., Ebert, D. and Van Elst, L.T. (2008) Frontolimbic glutamate alterations in first episode schizophrenia: Evidence from a magnetic resonance spectroscopy study. World Journal of Biological Psychiatry, 9, 59-63. doi:10.1080/15622970701227811

[5] Christison, G.W., Casanova, M.F., Weinberger, D.R., Rawlings, R. and Kleinman, J.E. (1989) A quantitative investigation of hippocampal pyramidal cell size, shape, and variability of orientation in schizophrenia. Archives of General Psychiatry, 46, 1027-1032. doi:10.1001/archpsyc.1989.01810110069010

[6] McGlashan, T.H. and Hoffman, R.E. (2000) Schizophrenia as a disorder of developmentally reduced synaptic connectivity. Archives of General Psychiatry, 57, 637648. doi:10.1001/archpsyc.57.7.637

[7] Duan, X., Chang, J.H., Ge, S., Faulkner, R.L., Kim, J.Y., Kitabatake, Y., Liu, X.B., Yang, C.H., Jordan, J.D., Ma, D.K., Liu, C.Y., Ganesan, S., Cheng, H.J., Ming, G.L., Lu, B. and Song, H. (2007) Disrupted-in-schizophrenia 1 regulates integration of newly generated neurons in the adult brain. Cell, 130, 1146-1158. doi:10.1016/j.cell.2007.07.010

[8] Reif, A., Fritzen, S., Finger, M., Strobel, A., Lauer, M., Schmitt, A. and Lesch, K.P. (2006) Neural stem cell proliferation is decreased in schizophrenia, but not in depression. Molecular Psychiatry, 11, 514-522. doi:10.1038/sj.mp.4001791

[9] Ikemoto, K., Nishimura, A., Oda, T., Nagatsu, I. and Nishi, K. (2003) Number of striatal D-neurons is reduced in autopsy brains of schizophrenics. Legal Medicine, 5, S221-S224. doi:10.1016/S1344-6223(02)00117-7

[10] Jaeger, C.B., Teitelman, G., Joh, T.H., Albert, V.R., Park, D.H. and Reis, D.J. (1983) Some neurons of the rat central nervous system contain aromatic L-amino acid decarboxylase but not monoamines. Science, 219, 12331235. doi:10.1126/science.6131537

[11] Boulton, A.A. (1974) Amines and theories in psychiatry. Lancet, 2, 7871.

[12] Boulton, A.A. and Juorio, A.V. (1979) The tyramines: Are they involved in the psychoses? Biological Psychiatry, 14, 413-419.

[13] Komori, K., Fujii, T., Karasawa, N., Yamada, K., Sakai, M. and Nagatsu, I. (1991) Some neurons of the mouse cortex and caudo-putamen contain aromatic L-amino acid decarboxylase but monoamines. Acta Histochemica et Cytochemica, 24, 571-577. doi:10.1267/ahc.24.571

[14] Jaeger, C.B., Ruggiero, D.A., Albert, V.R., Joh, T.H. and Reis, D.J. (1984) Immunocytochemical localization of aromatic-L-amino acid decarboxylase. In: Björklund, A. and Hökfelt, T., Eds., Handbook of Chemical Neuroanatomy. 2: Classical Transmitters in the CNS, Part I. Elsevier, Amsterdam, 387-408.

[15] Jaeger, C.B., Ruggiero, D.A., Albert, V.R., Park, D.H., Joh, T.H. and Reis, D.J. (1984) Aromatic L-amino acid decarboxylase in the rat brain: Immunocytochemical lo- calization in neurons of the rat brain stem. Neuroscience, 11, 691-713. doi:10.1016/0306-4522(84)90053-8

[16] Tashiro, Y., Kaneko, T., Sugimoto, T., Nagatsu, I., Kikuchi, H. and Mizuno, N. (1989) Striatal neurons with aromatic L-amino acid decarboxylase-like immunore-activity in the rat. Neuroscience Letters, 100, 29-34. doi:10.1016/0304-3940(89)90655-1

[17] Mura, A., Linder, J.C., Young, S.J. and Groves, P.M. (2000) Striatal cells containing aromatic L-amino acid decarboxylase: An immunohistochemical comparison with other classes of striatal neurons. Neuroscience, 98, 501511. doi:10.1016/S0306-4522(00)00154-8

[18] Ikemoto, K., Kitahama, K., Jouvet, A., Arai, R., Nishimura, A., Nishi, K. and Nagatsu, I. (1997) Demonstration of L-dopa decarboxylating neurons specific to human striatum. Neuroscience Letters, 232, 111-114. doi:10.1016/S0304-3940(97)00587-9

[19] Ikemoto, K., Kitahama, K., Jouvet, A., Nishimura, A., Nishi, K., Maeda, T. and Arai, R. (1998) A dopaminesynthesizing cell group demonstrated in the human basal forebrain by dual labeling immunohistochemical technique of tyrosine hydroxylase and aromatic L-amino acid decarboxylase. Neuroscience Letters, 243, 129-132. doi:10.1016/S0304-3940(98)00103-7

[20] Kitahama, K., Ikemoto, K., Jouvet, A., Nagatsu, I., Sakamoto, N. and Pearson, J. (1998) Aromatic L-amino acid decarboxylase and tyrosine hydroxylase immunohisto-chemistry in the adult human hypothalamus. Journal of Chemical Neuroanatomy, 16, 43-55. doi:10.1016/S0891-0618(98)00060-X

[21] Kitahama, K., Ikemoto, K., Jouvet, A., Araneda, S., Nagatsu, I., Raynaud, B., Nishimura, A., Nishi, K. and Niwa, S. (2009) Aromatic L-amino acid decarboxylase-immunoreactive structures in human midbrain, pons, and medulla. Journal of Chemical Neuroanatomy, 38, 130-140. doi:10.1016/j.jchemneu.2009.06.010

[22] Ikemoto, K. (2004) Significance of human striatal Dneurons: Implications in neuropsychiatric functions. Progress in Neuro-Psychopharmacology and Biological Psychiatry, 28, 429-434. doi:10.1016/j.pnpbp.2003.11.017

[23] Bunzow, J.R., Sonders, M.S., Arttamangkul, S., Harrison, L.M., Zhang, G., Quigley, D.I., Darland, T., Suchland, K.L., Pasumamula, S., Kennedy, J.L., Olson, S.B., Magenis, R.E., Amara, S.G. and Grandy, D.K. (2001) Amphetamine, 3,4-methylenedioxymethamphetamine, lysergic acid diethylamide, and metabolites of the catecholamine neurotransmitters are agonists of a rat trace amine recaptor. Molecular Pharmacology, 60, 1181-1188.

[24] Borowsky, B., Adham, N., Jones, K.A., Raddatz, R., Artymyshyn, R., Ogozalek, K.L., Durkin, M.M., Lakhlani, P.P., Bonini, J.A., Pathirana, S., Boyle, N., Pu, X., Kouranova, E., Lichtblau, H., Ochoa, F.Y., Branchek, T.A. and Gerald, C. (2001) Trace amines: Identification of a family of mammalian G protein-coupled receptors. Proceedings of the National Academy of Sciences of USA, 98, 8966-8971. doi:10.1073/pnas.151105198

[25] Miller, G.M. (2011) The emerging role of trace amineassociated receptor 1 in the functional regulation of monoamine transporters and dopaminergic activity. Jour- 
nal of Neurochemistry, 116, 164-176. doi:10.1111/j.1471-4159.2010.07109.x

[26] Xie, Z. and Miller, G.M. (2007) Trace amine-associated receptor 1 is a modulator of the dopamine transporter. Journal of Pharmacology and Experimental Therapeutics, 321, 128-136. doi:10.1124/jpet.106.117382

[27] Xie, Z. and Miller, G.M. (2009) Trace amine-associated receptor 1 as a monoaminergic modulator in brain. Biochemical Pharmacology, 78, 1095-1104. doi:10.1016/j.bcp.2009.05.031

[28] Lindemann, L., Meyer, C.A., Jeanneau, K., Bradaia, A., Ozmen, L., Bluethmann, H., Bettler, B., Wettstein, J.G., Borroni, E., Moreau, J.L. and Hoener, M.C. (2008) Trace amine-associated receptor 1 modulates dopaminergic activity. Journal of Pharmacology and Experimental Therapeutics, 324, 948-956. doi:10.1124/jpet.107.132647

[29] Zucchi, R., Chiellini, G., Scanlan, T.S. and Grandy, D.K. (2006) Trace amine-associated receptors and their ligands. British Journal of Pharmacology, 149, 967-978. doi:10.1038/sj.bjp.0706948

[30] Bradaia, A., Trube, G., Stalder, H., Norcross, R.D., Ozmen, L., Wettstein, J.G., Pinard, A., Buchy, D., Gassmann, M., Hoener, M.C. and Bettler, B. (2009) The selective antagonist EPPTB reveals TAAR1-mediated regulatory mechanisms in dopaminergic neurons of the mesolimbic system. Proceedings of the National Academy of Sciences of USA, 106, 20081-20086.

[31] Revel, F.G., Moreau, J.L., Gainetdinov, R.R., Bradaia, A., Sotnikova, T.D., Mory, R., Durkin, S., Zbinden, K.G., Norcross, R., Meyer, C.A., Metzler, V., Chaboz, S., Ozmen, L., Trube, G., Pouzet, B., Bettler, B., Caron, M.G., Wettstein, J.G. and Hoener, M.C. (2011) TAAR1 activation modulates monoaminergic neurotransmission, preventing hyperdopaminergic and hypoglutamatergic activity. Proceedings of the National Academy of Sciences of
USA, 108, 8485-8490. doi:10.1073/pnas.1103029108

[32] Panas, H.N., Lynch, L.J., Vallender, E.J., Xie, Z., Chen, G.L., Lynn, S.K., Scanlan, T.S. and Miller, G.M. (2010) Normal thermoregulatory responses to 3-iodothyronamine, trace amines and amphetamine-like psychostimulants in trace amine associated receptor 1 knockout mice. Journal of Neuroscience Research, 88, 1962-1969.

[33] Wolinsky, T.D., Swanson, C.J., Smith, K.E., Zhong, H., Borowsky, B., Seeman, P., Branchek, T. and Gerald, C.P. (2007) The Trace Amine 1 receptor knockout mouse: An animal model with relevance to schizophrenia. Genes, Brain and Behavior, 6, 628-639. doi:10.1111/j.1601-183X.2006.00292.x

[34] Ikemoto, K. (2008) Striatal D-neurons: In new viewpoints for neuropsychiatric research using post-mortem brains. Fukushima Journal of Medical Science, 54, 1-3.

[35] Degreef, G., Ashtari, M., Bogerts, B., Bilder, R.M., Jody, D.N., Alvir, J.M. and Lieberman, J.A. (1992) Volumes of ventricular system subdivisions measured from magnetic resonance images in first-episode schizophrenic patients. Archives of General Psychiatry, 49, 531-537. doi:10.1001/archpsyc.1992.01820070025004

[36] Horga, G., Bernacer, J., Dusi, N., Entis, J., Chu, K., Hazlett, E.A., Haznedar, M.M., Kemether, E., Byne, W. and Buchsbaum, M.S. (2011) Correlations between ventricular enlargement and gray and white matter volumes of cortex, thalamus, striatum, and internal capsule in schizophrenia. European Archives of Psychiatry and Clinical Neuroscience, 261, 467-476. doi:10.1007/s00406-011-0202-x

[37] Kippin, T.E., Kapur, S. and van der Kooy, D. (2005) Dopamine specifically inhibits forebrain neural stem cellproliferation, suggesting a novel effect of antipsychotic drugs. Journal of Neuroscience, 25, 5815-5023. doi:10.1523/JNEUROSCI.1120-05.2005 